\title{
STUDY OF RHEOLOGICAL CHARACTERISTICS OF FERMENTED MILK PASTE WITH SPICES
}

\author{
Galyna Polishchuk ${ }^{1}$, Uliana Kuzmyk ${ }^{2 \bowtie}$, Nataliia Yushchenko ${ }^{3}$, Tetiana Osmak ${ }^{4}$, Mykhailo \\ Kurmach ${ }^{5}$, Oksana Bass ${ }^{6}$, Oksana Kyrychenko ${ }^{7}$ \\ ${ }^{1}$ Department of Milk and Dairy Product Technology, National University of Food Technologies, Kyiv, Ukraine, 01601 \\ ORCID: https://orcid.org/0000-0003-3013-3245 \\ ${ }^{2}$ Department of Milk and Dairy Product Technology, National University of Food Technologies, Kyiv, Ukraine, 01601 \\ ORCID: https://orcid.org/0000-0003-2617-006X \\ ${ }^{3}$ Department of Restaurant Technology and Ayurvedic Products, National University of Food Technologies, Kyiv, Ukraine \\ ORCID: https://orcid.org/0000-0002-4277-5782 \\ ${ }^{4}$ Department of Milk and Dairy Product Technology, National University of Food Technologies, Kyiv, Ukraine, 01601 \\ ORCID: https://orcid.org/0000-0001-5548-1719 \\ ${ }^{5}$ L. V. Pisarzhevskii Institute of Physical Chemistry National Academy of Sciences of Ukraine, Kyiv, Ukraine, 03028 \\ ORCID: https://orcid.org/0000-0001-5649-161X \\ ${ }^{6}$ Department of Milk and Dairy Product Technology, National University of Food Technologies, Kyiv, Ukraine, 01601 \\ ORCID: https://orcid.org/0000-0001-7222-1388 \\ ${ }^{7}$ Department of Milk and Dairy Product Technology, National University of Food Technologies, Kyiv, Ukraine, 01601 \\ ORCID: https://orcid.org/0000-0002-2349-8716 \\ \Corresponding author: Uliana Kuzmyk, e-mail: ukuzmik@gmail.com
}

\section{ABSTRACT}

Research object: rheological characteristics of fermented milk pastes with spices. Investigated problem: according to the results of the degree of syneresis and rheological properties, the consistency of the product is characterized. This allows to improve and optimize the technological process for the production of fermented milk products. Main scientific results: the results of the dispersion analysis of spices show that their particle size is in the range of $250 \ldots 400$ microns. This size is optimal for the extraction of biologically active substances of spices, which will contribute to greater assimilation by the human body. And also optimally to avoid caking of raw materials and the manifestation of moisture-absorbing properties.

It was found that the degree of syneresis of fermented milk pastes with spices is within $10 \%$. With the addition of cinnamon and fenugreek spices, the degree of syneresis is lower compared to other examples. This is due to the fact that spices contain a solution of fiber, which allows them to retain free moisture. The spice cinnamon is a dried bark that naturally contains polysaccharides, while fenugreek contains up to $30 \%$ mucus, which also has a high moisture-absorbing capacity. With such a low serum separation, the stabilizing effect is sufficient to prevent spontaneous whey separation.

Based on the results of the rheological properties of the product, it was established that fermented milk pastes belong to viscoplastic systems with a normal consistency. There was a slight difference in the shear stress index for pastes based on fermented milk low-fat soft dietary cheese and sour cream with a fat mass fraction of $20 \%$ - by an average of $50 \mathrm{~Pa}$. This characteristic is due to the hydrophilic characteristics of the protein.

The area of practical use of the research results: scientific research concerns the technology of dairy products in the food industry.

Innovative technological product: the obtained scientific result is an opportunity to improve the technological process of fermented milk products.

The scope of implementation of an innovative technological product: the results obtained give grounds to assert the ability to translate into a real industrial creation.

(C) The Author(s) 2021. This is an open access article under the Creative Commons CC BY license

\section{Introduction}

\section{1. The object of research}

Fermented milk pastes are products made from fermented milk cheese and/or sour cream with the addition of flavoring fillers. 
The consistency of fermented milk pastes is an important aspect of their quality. Therefore, the object of the study is to study the rheological properties of fermented milk pastes while developing a new technology.

\section{2. Problem description}

One of the important characteristics of fermented milk products is consistency, which can be characterized by rheological properties. These include shear, compression and surface properties. Shear properties most fully characterize the consistency of fermented milk products. They characterize the behavior of a product under stress conditions, the main indicators of which are stress, deformation and deformation rate $[1,2]$.

Fermented milk pastes are characterized by a thixotropic structure of the coagulation type. Therefore, their consistency depends on the correct process taking place in the production of fermented milk products [3].

\section{3. Suggested solution to the problem}

It is found that the formation of rheological properties of fermented milk products affects the content of casein [4]. With an increase in the protein concentration, the rate of gelation increases as a result of an increase in the contacts of intermolecular spatial bonds.

It is known that the strength of the curd, the degree of its recovery after destruction and syneresis depend on the microorganisms of the starter culture and the technology for the production of the fermented milk product. In particular, the use of ferments capable of producing mucus, even in small quantities, improves the rheological parameters of fermented milk products [5].

The product's resistance to syneresis is also an important quality indicator. The strength of the bonds between particles, the form of the connection, and the interactions between different proteins and functional ingredients affect homogeneity and syneresis $[6,7]$.

Therefore, the study of the rheological properties of fermented milk pastes is relevant for the optimization of technological processes.

The aim of research is to study the rheological characteristics of fermented milk pastes with spices. This will improve and optimize the technological process for the production of fermented milk products.

\section{Materials and Methods}

For the study, let's select fermented milk pastes, the formulation of which was developed by preliminary research (Table 1) [8].

Table 1

Spice compositions

\begin{tabular}{|c|c|c|c|c|}
\hline \multirow{2}{*}{$\begin{array}{l}\text { Composi- } \\
\text { tion, No. }\end{array}$} & \multirow{2}{*}{ Component composition } & \multirow{2}{*}{$\begin{array}{l}\text { Recommended ra- } \\
\text { tio of components }\end{array}$} & \multicolumn{2}{|c|}{ Recommended content for $\mathbf{f} / \mathrm{m}$ pastes based on } \\
\hline & & & Cheese $\mathbf{f} / \mathbf{m}$ & sour cream \\
\hline 1 & allspice, ginger, cinnamon & $1: 1: 1$ & $0.3-0.33$ & $0.33-0.36$ \\
\hline 2 & cloves, allspice, ginger & $0.8: 1: 1$ & $0.27-0.28$ & $0.28-0.29$ \\
\hline 3 & anise, cloves, ginger, black pepper & 1:0.8:1:1 & $0.37-0.38$ & $0.38-0.4$ \\
\hline 4 & allspice, ginger, cardamon, fenugreek & $1: 1: 0.8: 1.2$ & $0.39-0.4$ & $0.4-0.42$ \\
\hline 5 & anise, ginger, nutmeg, black pepper & $1: 1: 1: 1$ & $0.4-0.44$ & $0.44-0.48$ \\
\hline
\end{tabular}

The dispersed composition of grinding dry spices was evaluated by the average particle diameter, determined mechanically using a set of sieves.

The degree of syneresis of the pastes was determined by the centrifugal method. The experimental sample, after mixing, was introduced into centrifuge measuring tubes in an amount of $10 \mathrm{~cm}^{3}$ and centrifuged for $30 \mathrm{~min}$ at a speed of $3000 \mathrm{~min}^{-1}$. The volume of released serum $\left(\mathrm{cm}^{3}\right)$ was determined every $5 \min [9]$.

The rheological properties of fermented milk pastes were determined on a Rheotest II rotational viscometer with a cylinder-cylinder $\mathrm{S} / \mathrm{N}$ measuring system by taking the deformation (flow) kinetics curves [10]. 
The obtained measurement results and the graphical presentation of the experimental data were carried out using standard statistical processing programs Microsoft Excel 2010. The accuracy of the results obtained was provided by a three to fivefold repeatability of experiments.

\section{Results}

For the complete extraction of soluble biologically active substances, spices must be crushed before using in fermented milk pastes. This will also contribute to the greater absorption of extractives by the human body. The results of the dispersed analysis of spice particles are shown in Fig. $\mathbf{1}$.

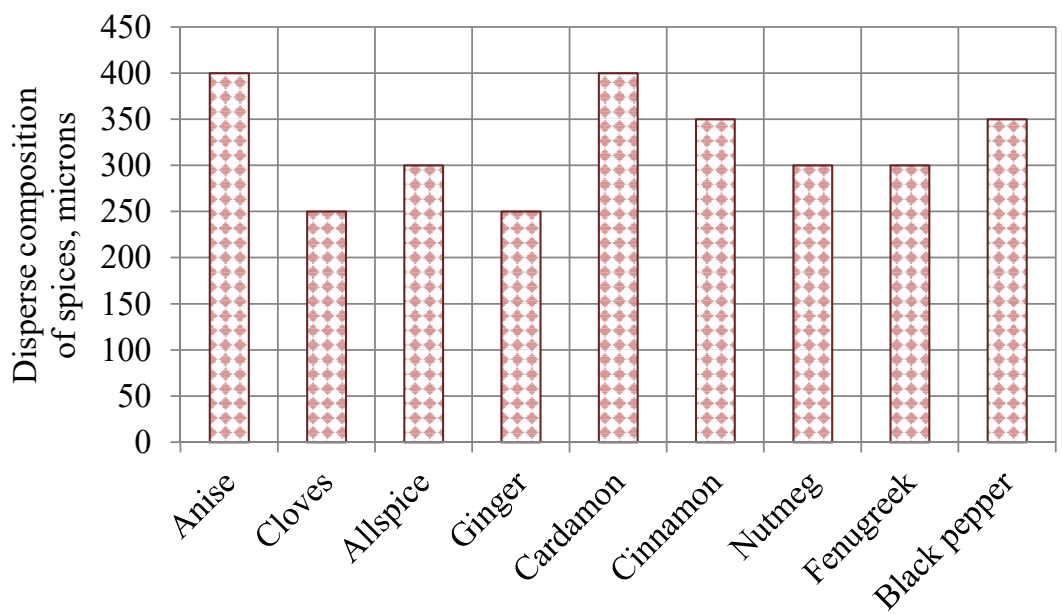

Fig. 1. Disperse composition of spices

According to the results of dispersed analysis, the main fractions of spice particles are in the range of $250 \ldots 400$ microns. This particle size is optimal for the extraction of biologically active substances of spices, as well as to avoid caking of raw materials.

One of the main characteristics of fermented milk pastes is the degree of syneresis, which characterizes their water-holding properties. For the research, the developed spice compositions were used, given in Table 1.

The degree of syneresis of fermented milk pastes with spices is shown in Fig. 2. From the data obtained, it can be seen that this indicator is at the level of $10 \%$. With such a low serum separation, the stabilizing effect was sufficient to prevent spontaneous serum separation.

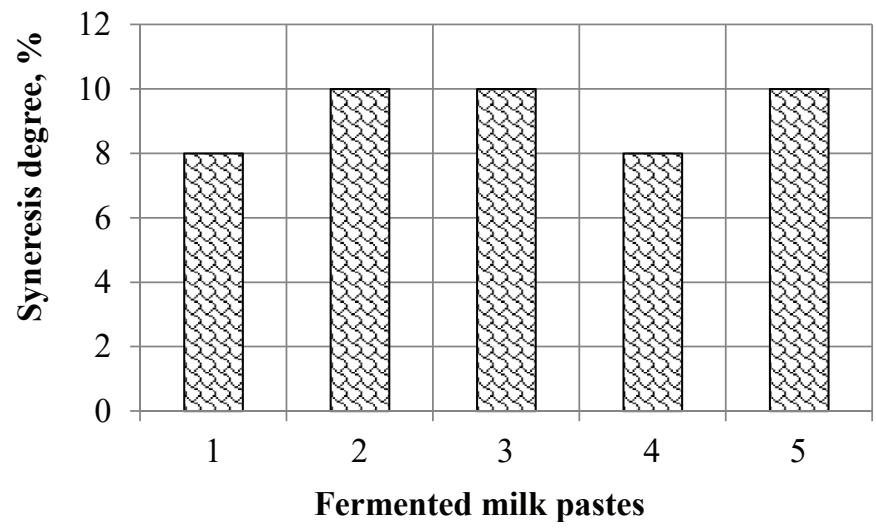

Fig. 2. Syneresis degree of fermented milk pastes

With the addition of the cinnamon included in the composition 1 and with the addition of the fenugreek included in the composition 5, the degree of syneresis is lower compared to other samples. This is due to the fact that spices contain a solution of fiber, which allows them to retain 
free moisture. The spice cinnamon is a dried bark that naturally contains polysaccharides, while fenugreek contains up to $30 \%$ mucus, which also has a high moisture-absorbing capacity.

To assess the consistency of the product, the rheological properties of fermented milk pastes were investigated. Based on the results obtained, rheological curves of the dependence of the shear stress and strain rate of the studied samples, shown in Fig. 3.

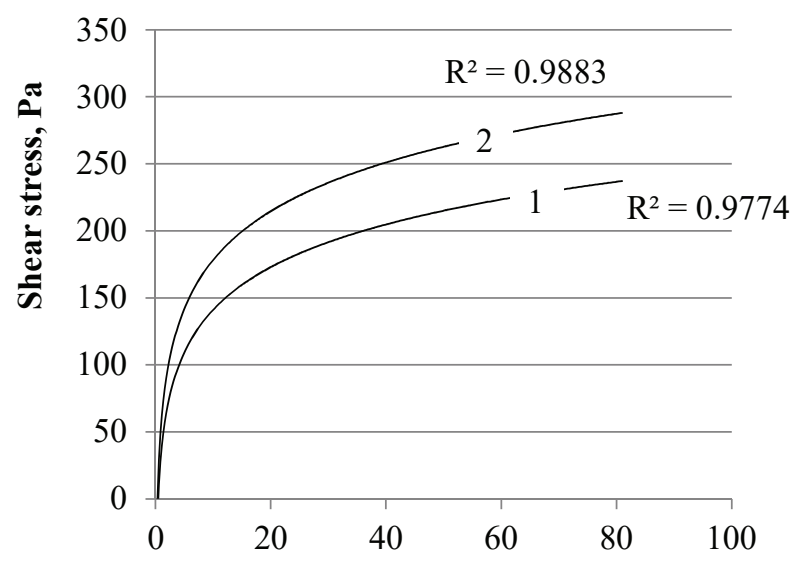

Straing rate, $1 / \mathrm{s}$

Fig. 3. Dependence of stress on the rate of deformation of fermented milk pastes with spices: 1 - fermented milk paste for new sour cream; 2 - fermented milk paste based on fermented milk cheese

From the analysis of the dependences of the shear stress on the strain rate, it was found that fermented milk pastes based on soft, low-fat dietary fermented milk cheese and sour cream with a fat mass fraction of $20 \%$ exhibit a similar character. There was a slight difference in the shear stress index - on average by $50 \mathrm{~Pa}$, which is due to the hydrophilic characteristics of the protein.

\section{Discussion}

To assess the quality of fermented milk products, it is advisable to study their ability to syneresis. It was investigated [6-9] that with an increase in the content of dry substances with hydrophilic properties, the amount of free moisture decreases. And thus the degree of syneresis decreases.

It was found that the degree of syneresis of fermented milk pastes with spices is within $10 \%$ (Fig. 2). When spices are added with a fineness of 250...400 microns (Fig. 1), the separation of whey will be insignificant, which will prevent spontaneous separation of moisture. This is due to the fact that spices contain a solution of fiber, which allows to retain free moisture.

It has been studied $[1,2,4]$ that the structure of fermented milk products is determined by many factors. From mechanical stress, fermentation parameters, etc. the structural characteristics of the product depend. The efficiency of the technological process can be increased by examining the rheological properties of the fermented milk product.

Analyzing the data obtained, it can be assumed to what type of rheological bodies the fermented milk pastes belong. According to the results of rheological properties, it was found that fermented milk pastes belong to viscoplastic systems with normal consistency. The shear stress index for them is in the range from 100 to $500 \mathrm{~Pa}$. There was a slight difference in the shear stress index for pastes based on fermented milk low-fat soft dietary cheese and sour cream with a fat mass fraction of $20 \%$ - by an average of $50 \mathrm{~Pa}$.

The application of these research methods is limited. Such methods are suitable for the study of structured dairy products, which are characterized by a weakly structured, viscoplastic, plastic and elastic system. Although there are certain restrictions on the description of deformation processes, the results of the research carried out can be used to optimize and improve the technology of fermented milk products. 


\section{Conclusions}

1. According to the results in the composition of fermented milk pastes, spices with a fineness of 250...400 microns are used. With this particle size, spices will better show their moisture-absorbing properties. It was investigated that the degree of syneresis of fermented milk pastes with spices is within $10 \%$. With such a low serum separation, the stabilizing effect is sufficient to prevent spontaneous whey separation.

2. Based on the results of the rheological properties of the product, it has been established that fermented milk pastes are viscoplastic systems with normal consistency. There was a slight difference in the shear stress index for pastes based on fermented milk low-fat soft dietary cheese and sour cream with a fat mass fraction of $20 \%$ - by an average of $50 \mathrm{~Pa}$. This characteristic is due to the hydrophilic characteristics of the protein.

\section{References}

[1] Mokoonlall, A., Nöbel, S., Hinrichs, J. (2016). Post-processing of fermented milk to stirred products: Reviewing the effects on gel structure. Trends in Food Science \& Technology, 54, 26-36. doi: http://doi.org/10.1016/j.tifs.2016.05.012

[2] Dello Staffolo, M., Sato, A. C. K., Cunha, R. L. (2017). Utilization of Plant Dietary Fibers to Reinforce Low-Calorie Dairy Dessert Structure. Food and Bioprocess Technology, 10 (5), 914-925. doi: http://doi.org/10.1007/s11947-017-1872-9

[3] Bouisfi, A., Chaoui, M. (2018). Effect of the freezing point of raw milk on the protein content and rheology of the curd, obtained by combining acid and rennet coagulation. FME Transactions, 46 (4), 644-650. doi: http://doi.org/10.5937/fmet1804644b

[4] Tarhan, Ö., Kaya, A. (2021). Investigation of the compositional and structural changes in the proteins of cow milk when processed to cheese. LWT, 151, 112102. doi: http://doi.org/10.1016/j.lwt.2021.112102

[5] Potemska, O. I., Kihel, N. F., Danylenko, S. H., Zakrevska, V. M. (2016). Vidbir molochnokyslykh bakterii za reolohichnymy kharakterystykamy. Prodovolchi resursy, 7, 92-99.

[6] Day, L., Williams, R. P. W., Otter, D., Augustin, M. A. (2015). Casein polymorphism heterogeneity influences casein micelle size in milk of individual cows. Journal of Dairy Science, 98 (6), 3633-3644. doi: http://doi.org/10.3168/jds.2014-9285

[7] Kusio, K., Szafrańska, J. O., Radzki, W., Sołowiej, B. G. (2020). Effect of Whey Protein Concentrate on Physicochemical, Sensory and Antioxidative Properties of High-Protein Fat-Free Dairy Desserts. Applied Sciences, 10 (20), 7064. doi: http://oi.org/ 10.3390/app10207064

[8] Goots, V., Yushchenko, N., Kuzmyk U. (2018). Development of mathematic model of spiced sour-milk pastas quality. Food and Environment Safety, 2, 224-232.

[9] Rudiuk, V., Pasichnyi, V., Khorunzha, T., Krasulya, O. (2019). Investigation of the influence of the use of protein concentrates on the rheological index of sour-milk products and their shelf-life. Food Industry, 25, 70-77. doi: http://doi.org/10.24263/22252916-2019-25-11

[10] Kochubei-Lytvynenko, O., Yatsenko, O., Yushchenko, N., Kuzmyk, U. (2018). Astabilizing system for butter pastes based on the dry concentrates of milk protein. Eastern-European Journal of Enterprise Technologies, 5 (11 (95)), 30-36. doi: http://doi.org/ 10.15587/1729-4061.2018.143105 